\title{
Interceptações de pragas quarentenárias e ausentes não regulamentadas em material vegetal importado
}

\author{
Marcelo Lopes-da-Silva(1), Norton Polo Benito(1), Marcio Martinello Sanches ${ }^{(1)}$, \\ Abi Soares dos Anjos Marques(2), Denise Návia(1), Vilmar Gonzaga( ${ }^{(1)}$, Marta Aguiar Sabo Mendes ${ }^{(1)}$, \\ Olinda Maria Martins ${ }^{(1)}$, Arailde Fontes Urben ${ }^{(1)}$ e Fernanda Rausch Fernandes ${ }^{(2)}$
}

\begin{abstract}
(1)Embrapa Recursos Genéticos e Biotecnologia, Parque Estação Biológica, Caixa Postal 02372, CEP 70770-917 Brasília, DF, Brasil. E-mail: marcelo.lopes.silva@embrapa.br, norton.benito@embrapa.br, marcio.sanches@embrapa.br, denise.navia@embrapa.br, vilmar.gonzaga@embrapa.br, marta.mendes@embrapa.br, olinda.martins@embrapa.br, arailde.urben@embrapa.br (2)Embrapa Quarentena Vegetal, Caixa Postal 02372, CEP 70770-917 Brasília, DF, Brasil. E-mail: abi.marques@embrapa.br, fernanda.rausch@embrapa.br
\end{abstract}

Resumo - O objetivo deste trabalho foi avaliar as informações qualitativas e quantitativas sobre as interceptações de pragas ausentes não regulamentadas e quarentenárias em material vegetal importado. As informações sobre interceptações de pragas pelo serviço de quarentena vegetal da Embrapa, no período de 1977 a 2013, foram obtidas em um banco de dados, atas laboratoriais e listas de interceptação publicadas. As interceptações foram analisadas de acordo com regulamentação das pragas, espécie vegetal, parte vegetal importada e origem. O material foi categorizado em sementes botânicas e material de propagação vegetativa. No período do levantamento, foram interceptadas 75 espécies de pragas em 114 eventos de interceptação. Fungos, vírus e ácaros constituem a maior parte das interceptações, e a maioria delas ocorreu em lírio, oliveira, trigo, uva, arroz, batata e maçã. A taxa média anual de infestação/infecção do material vegetal analisado é de $2 \%$ dos processos de importação. O material para propagação vegetativa apresentou maior taxa de infestação/infecção por pragas do que as sementes botânicas. Das espécies-pragas interceptadas, $63 \%$ não são regulamentadas como quarentenárias para o Brasil. Esses resultados indicam a necessidade premente de revisão da atual lista de pragas quarentenárias do País.

Termos para indexação: defesa fitossanitária, intercâmbio de germoplasma, patologia de sementes, quarentena de pós-entrada, sanidade de material de propagação vegetativa, sanidade vegetal.

\section{Interceptions of quarantine and absent non-regulated pests in imported plant material}

\begin{abstract}
The objective of this work was to evaluate qualitative and quantitative information on interceptions of quarantine and absent non-regulated pests in imported plant material. Information concerning pest interceptions by Embrapa's plant quarantine service during the period of 1977-2013 was obtained from a database, laboratory reports, and published lists of intercepted pests. Data interceptions were evaluated according to pest regulations, plant species, imported plant parts, and origin of importation. The plant material was categorized as botanical seeds and plant material for vegetative propagation. In the survey period, 75 pest species were intercepted in 114 interception events. Fungi, viruses, and mites were the most intercepted ones, and most interceptions occurred in lily, olive, wheat, grapes, rice, potato, and apple. The average annual rate of infestation/infection of the evaluated plant material was $2 \%$ of the import processes. The material for vegetative propagation had a higher rate of infestation/infection with pests than botanical seeds. Of the intercepted pests species, $63 \%$ are not regulated as quarantine pests for Brazil. These results indicate the urgent need to review the current list of quarantine pests in the country.
\end{abstract}

Index terms: plant protection, germplasm exchange, seed pathology, post-entry quarantine, sanity of plant material for vegetative propagation, plant health.

\section{Introdução}

O intercâmbio de material vegetal entre os países é uma atividade indispensável para o enriquecimento do patrimônio genético, e possibilita geração de novas variedades para o aumento da produção agrícola. Atualmente, a humanidade depende de aproximadamente uma dezena das 300.000 espécies de plantas conhecidas para suprir $80 \%$ de suas necessidades calóricas (McCouch et al., 2013). 
No Brasil, assim como em outros países, a maior parte dos produtos cultivados é de origem exótica (Guerra et al., 2015).

Um dos principais problemas da agricultura é a ocorrência, nos cultivos agrícolas, de organismos considerados nocivos que provocam redução na produção de alimentos, fibras e bioenergia. Esses organismos se enquadram no conceito de praga, que é aplicável a qualquer espécie, raça ou biótipo de planta, animal ou agente patogênico que danifica plantas ou produtos vegetais (International Plant Protection Convention, 2012). Inevitavelmente, o trânsito de material vegetal importado, sem os cuidados apropriados, traz o risco de introdução de pragas em áreas indenes (Waterworth \& White, 1982). A dispersão mundial de pragas agrícolas ocorre em taxas crescentes e esse fenômeno pode ser atribuído ao aumento do comércio entre os países e, também, às mudanças climáticas (Hulme, 2009; Bebber et al., 2014). A maior parte de relatos de casos de novas pragas pode ser atribuída à ação humana, como o transporte de vegetais pelo mundo. Diante desse cenário, torna-se um desafio aliar segurança e eficiência no intercâmbio científico e comercial de material vegetal (Lopes-da-Silva et al., 2014; Gonzaga et al., 2015; Sugayama et al., 2015).

A quarentena vegetal preconiza atividades destinadas a prevenir a introdução e/ou disseminação de pragas agrícolas quarentenárias ou assegurar seu controle oficial (International Plant Protection Convention, 2012; Legrand, 2012). Em 1995 foi instituído o acordo SPS (Acordo sobre Medidas Sanitárias e Fitossanitárias), que tem como objetivo garantir que as medidas sanitárias e fitossanitárias, elaboradas pelos países membros da Organização Mundial do Comércio (OMC), não se transformem em obstáculos desnecessários ao comércio. Desde então, as pragas passarão a ser classificadas como quarentenárias quando representarem risco econômico potencial para alguma região ou país (International Plant Protection Convention, 1997).

As informações qualitativas e quantitativas sobre as interceptações de pragas quarentenárias e pragas ausentes não regulamentadas são de extrema relevância para a elaboração de políticas de gerenciamento de risco de introdução de pragas no Brasil. Atualmente, dados de interceptação de pragas não são utilizados para elaboração de legislação de proteção fitossanitária.
O objetivo deste trabalho foi avaliar as informações qualitativas e quantitativas sobre as interceptações de pragas ausentes não regulamentadas e quarentenárias em material vegetal importado.

\section{Material e Métodos}

Os registros de detecções de cada unidade de análise do Laboratório de Quarentena Vegetal, na Embrapa Recursos Genéticos e Biotecnologia, credenciada como Estação Quarentenária de Germoplasma Vegetal (EQGV), foram obtidos de um sistema de informações, de atas laboratoriais e de publicações. Esse levantamento, realizado em 2014, reuniu as informações de interceptações entre 1977 e 2013. A maior parte dos registros foi obtida do Sibrargen (Sistema Brasileiro de Informações em Recursos Genéticos), que é um sistema interno da Embrapa para o gerenciamento de informações de coleções, intercâmbio e quarentena de germoplasma vegetal. Parte dos registros das detecções já havia sido publicada nos trabalhos de Warwick et al. (1983), Marques et al. (1995) e Marinho et al. (2003).

Foram compilados os dados de interceptação e avaliadas, em termos absolutos, as principais fontes de pragas (países, plantas ou partes de plantas importadas), considerando apenas as pragas ausentes do Brasil à época de uma dada importação. Pragas ausentes, não regulamentadas como quarentenárias, foram denominadas "ausentes não regulamentadas". As pragas com histórico de detecção anterior a 1997 foram enquadradas na legislação atual, conforme a Instrução Normativa 41 do Mapa, de $1^{\circ}$ de julho de 2008 e modificações providas pela Instrução Normativa 59 do Mapa, de 18 de dezembro de 2013 (Brasil, 2013). Esse procedimento permitiu a comparação entre o que foi reconhecido como praga quarentenária e o que foi detectado como praga ausente no Brasil na EQGV.

Todas as informações levantadas sobre o processo de importação foram dispostas em uma planilha geral. Os processos de importação foram identificados quanto ao ano, origem, espécie vegetal, parte vegetal e interceptação. Dessa planilha geral, todas as importações com interceptação de praga ausente do Brasil foram organizadas em uma nova tabela, atrelando-se as informações de ano, país de origem, espécie vegetal, além de serem adicionadas novas qualificações, como espécie e grupo da praga e seu status regulatório atual. Procedeu-se a uma consulta à 
literatura para verificar a situação atual de ocorrência da praga no Brasil, porque essa situação poderia ser diferente daquela na época da interceptação.

Para as análises foi considerado o número de espécies detectadas por grupo de pragas (ácaros, fungos, insetos, nematoides, procariontes, vírus e viroides), categorizadas em quarentenárias e ausentes não regulamentadas. Também foi considerado $o$ número de interceptações de cada praga. $\mathrm{O}$ material vegetal importado foi categorizado em sementes botânicas e material de propagação vegetativa (mudas, estacas, bulbos, tubérculos), além de frutos e madeira.

As interceptações de pragas também foram analisadas de acordo com o país de origem. O número de interceptações foi correlacionado com o número de importações e com o perfil das importações conforme a categorização do material vegetal importado. Essa categorização incluiu importações de sementes botânicas, de material de propagação vegetativa e a proporção dessas categorias no total de importações de cada país. As análises também foram realizadas de forma agregada, com base no conjunto de interceptações em material proveniente de todos os países. Para testar a hipótese de que a proporção de interceptação de pragas é maior em material de propagação vegetativa do que em sementes botânicas, utilizou-se o teste de qui-quadrado $\left(\chi^{2}\right)$. Com o objetivo de verificar quais fatores poderiam explicar o número de interceptações, foram organizados os dados do número de importações com interceptações e do número total de importações por países. O primeiro fator testado foi se o número de interceptações correlacionou-se com o número total de importações, por meio da significância do coeficiente de correlação de Pearson.

Em virtude do número discrepante de importações entre países, mesmo com uma correlação positiva e significante a $5 \%$ de probabilidade, outras análises foram realizadas. Foi testada a hipótese de que as proporções de importações com interceptação no total de importações, entre os países, seriam diferentes. Em virtude da existência de países com número de interceptações inferior a cinco, em vez do teste de $\chi^{2}$, utilizou-se o teste G. Por fim, testou-se, por meio de uma análise de regressão linear simples, a hipótese de que houve um aumento da taxa de interceptações (idp em \%) quando a quantidade de material de propagação vegetativa (estacas, bulbos, mudas) (mpv em \%) aumentava em relação à quantidade de sementes botânicas nas importações dos países. Essa análise foi realizada em razão de a EQGV receber sementes botânicas em maior quantidade para análises quarentenárias. Excluíram-se da análise de regressão dados de países com um número de envios inferior a 40 , pois a inclusão poderia alterar de forma tendenciosa os resultados analisados por uma estatística baseada em percentuais.

Diversas espécies interceptadas são oficialmente regulamentadas ou foram regulamentadas posteriormente à interceptação (Brasil, 2013). No entanto, em virtude de a legislação nacional restringir a movimentação de material vegetal com doenças ou pragas consideradas perigosas, todo o material com organismos exóticos foi destruído ou liberado apenas após a erradicação da praga.

\section{Resultados e Discussão}

O número total de processos de importação analisados, cujos dados foram recuperados do Sibrargen, foi de 5.267, no período considerado. O primeiro processo de importação com interceptação de uma praga ausente do Brasil ocorreu em 1985, oito anos após o início da quarentena. Além do período de 1977-1984, não houve registro de interceptações de pragas ausentes nos anos 1986, 1987, 1989, 1992, 1994, 1996, 1997 e 2000. A partir de 2002, ao menos uma praga foi interceptada no material vegetal analisado, anualmente, com exceção do ano de 2010, em que não houve interceptações (Figura 1). A frequência de interceptações foi variável, mas raramente foi superior a quatro por ano. Todavia, houve um pico significante de interceptações nos anos 2008 e 2009, o que foi causado pelo aumento de análises de amostras fiscais. De forma geral, não foi verificada tendência de aumento no número de interceptações nas últimas duas décadas (décadas de 2000 e 2010), considerando-se apenas os anos 2008 e 2009 como casos de exceção. De 2006 a 2010, a EQGV, por solicitação do Mapa, efetuou quarentena de material comercial importado. A maior parte das amostras fiscais foi analisada de 2007 a 2009 e era constituída de plantas ornamentais, que são fontes de disseminação de pragas agrícolas no comércio mundial (Karnkowski, 1999).

O número total de espécies de pragas interceptadas na EQGV foi 75 em 106 processos de importação (Tabela 1). Os grupos de pragas mais abundantes em 
número de espécies foram, pela ordem decrescente, fungos, vírus, ácaros e nematoides. O percentual desses organismos perfaz quase $90 \%$ das interceptações em número de espécies. Há diferenças entre os resultados qualitativos dessas interceptações em comparação com dados registrados por serviços de quarentena ao redor do mundo. Nos Estados Unidos, o grupo insetos foi o mais frequentemente interceptado em plantas e partes de plantas, nos postos de fronteiras, portos marítimos e bagagens de viajantes em aeroportos (McCullough et al., 2006). Já na China, os insetos e plantas são os organismos mais interceptados no Laboratório de Quarentena e Inspeção de Plantas de Shenzen (Zhang et al., 2011). Essa diferença pode ser atribuída ao fato que a EQGV analisa preferencialmente germoplasma para pesquisa, com predominância de amostras de sementes em pequenas quantidades, que são menos infestadas por insetos. Os artrópodes são interceptados de forma muito mais frequente em flores e frutos (McCullough et al., 2006). No presente trabalho verificou-se que os organismos mais interceptados foram vírus, fungos e nematoides. De forma oposta, fungos, nematoides e vírus foram os organismos quarentenários menos encontrados nas inspeções quarentenárias na China (Zhang et al.,

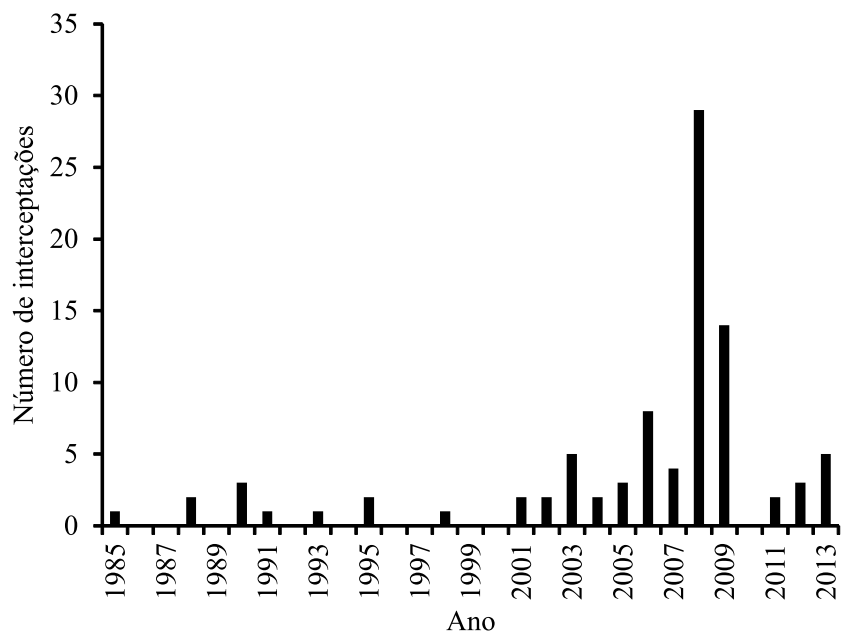

Figura 1. Número de interceptações de pragas ausentes não regulamentadas e quarentenárias, por ano, sobre material vegetal importado obtido da base de dados do Sibrargen (Sistema Brasileiro de Informações em Recursos Genéticos) e relatórios de unidades laboratoriais. Dados da Estação Quarentenária de Germoplasma Vegetal da Embrapa Recursos Genéticos e Biotecnologia (1977-2013).
2011). Os nematoides são o grupo de pragas menos interceptado nos Estados Unidos (McCullough et al., 2006). Por outro lado, na Europa, os nematoides foram o grupo de pragas mais interceptado sobre plantas para viveiros e bonsais, num percentual superior a $60 \%$, em relação às interceptações de pragas sobre esse tipo de material vegetal (Eschen et al., 2015). Na EQGV, a maioria das interceptações de nematoides ocorreu em material de propagação vegetativa, o que em parte corrobora Eschen et al. (2015), mas também houve algumas interceptações de nematoides em sementes.

No presente trabalho, vírus foi o grupo mais interceptado, o que indicou claramente que a detecção desse grupo de pragas foi dependente de técnicas laboratoriais mais complexas que sua simples inspeção visual. Esse grupo de pragas foi o menos detectado nas inspeções quarentenárias na China (Zhang et al., 2011) e nem foi mencionado nos levantamentos de interceptação de pragas nos Estados Unidos (McCullough et al., 2006). Bactérias e vírus foram constatados principalmente em mudas e, em menor proporção, em sementes. Essas constatações corroboram outras análises de interceptações de pragas (Karnkowski, 1999; McCullough et al., 2006; Zhang et al., 2011).

Constatou-se que houve associação entre o grupo de pragas interceptado e o tipo de material vegetal importado. Ácaros e insetos foram encontrados, na maior parte dos casos, em material de propagação vegetativa, enquanto fungos e nematoides foram indistintamente encontrados tanto em sementes como

Tabela 1. Interceptações de espécies de pragas quarentenárias e ausentes sem regulamentação por grupo de pragas, em material vegetal importado, em 106 processos de importação. Dados da Estação Quarentenária de Germoplasma Vegetal da Embrapa Recursos Genéticos e Biotecnologia (1977-2013).

\begin{tabular}{|c|c|c|c|c|c|c|}
\hline \multirow[t]{2}{*}{ Grupo } & \multicolumn{2}{|c|}{ Espécies } & \multicolumn{2}{|c|}{ Interceptações } & \multicolumn{2}{|c|}{ Total por grupo } \\
\hline & $\mathrm{Q}^{(1)}$ & $\mathrm{ANR}^{(2)}$ & Q & ANR & Espécies & Interceptações \\
\hline Ácaros & 4 & 8 & 6 & 10 & 12 & 16 \\
\hline Fungos & 5 & 20 & 6 & 20 & 25 & 26 \\
\hline Insetos & 6 & 1 & 6 & 1 & 7 & 7 \\
\hline Plantas & 1 & 1 & 1 & 1 & 2 & 2 \\
\hline Nematoides & 5 & 6 & 15 & 9 & 11 & 24 \\
\hline Bactérias & 3 & 2 & 3 & 2 & 5 & 5 \\
\hline Vírus & 4 & 9 & 24 & 10 & 13 & 34 \\
\hline Total dos gru & 28 & 47 & 61 & 53 & 75 & 114 \\
\hline
\end{tabular}

${ }^{(1)} \mathrm{Q}$, pragas quarentenárias; ${ }^{(2)} \mathrm{ANR}$, pragas ausentes não regulamentadas. 
em material de propagação vegetativa. Isso está de acordo com o relatado por McCullough et al. (2006) e Kenis et al. (2007), pois o material de propagação vegetativa fornece abrigo e alimento para os artrópodes (ácaros e insetos) sobreviverem ao período de transporte.

Considerando a categorização quanto à regulamentação quarentenária, mais da metade das espécies de pragas interceptadas (47) pertenceu à categoria de ausentes não regulamentadas, que são pragas sem informações de ocorrência no Brasil e não possuem o status de quarentenária. O número de pragas quarentenárias interceptadas pode ser considerado relativamente alto (28 espécies), pois o número de espécies de pragas regulamentadas foi muito menor que o número total de pragas não regulamentadas que estão ausentes do Brasil. Esse número de pragas quarentenárias interceptadas constituiu cerca de 5\% do número de pragas quarentenárias entre gêneros e espécies que são regulamentados para o Brasil (Brasil, 2013). Se, entretanto, for considerado o número total de interceptações, independentemente de espécies (114 nas 106 importações), 61 foram de pragas quarentenárias e 53 foram de pragas ausentes sem regulamentação (Tabela 1). Essa inversão de predominância na categoria se explica pelas várias interceptações do vírus quarentenário Lily symptomless virus (LSV) ocorridas no período de 2008 a 2009 em lírio importado da Holanda. Na época da interceptação, o LSV já estava em praticamente todas as regiões do mundo que são importantes na produção de lírio (Singh et al., 2008). Além de o estabelecimento da praga ocorrer por meio de plantio de material infectado, a disseminação é favorecida pela existência de afídeos vetores não persistentes que são praticamente cosmopolitas (Singh et al., 2008; Rivas, 2010).

A predominância de interceptações de pragas ainda não regulamentadas constitui uma informação importante para o sistema de defesa vegetal no Brasil. Atualmente, a regulamentação de pragas quarentenárias no Brasil se dá por um processo de análise de risco de pragas (ARP), que é prévio ao processo de importação do vegetal (Stancioli \& Sugayama, 2015). A ARP baseia-se apenas em informações e avaliações de risco e, assim, os dados de interceptação de estações quarentenárias podem ser úteis para a regulamentação de pragas quarentenárias. As informações de interceptações poderiam ser incorporadas no processo de ARP, pois podem indicar novas informações sobre hospedeiros e países de ocorrência de pragas. Também seriam valiosos os registros de sobrevivência de pragas durante uma importação, pois esse tipo de informação é essencial para ARP e não pode ser obtido de uma forma experimental. Na Europa, a maioria das pragas invasoras que se estabeleceram a partir de 1995 ainda não era regulamentada como quarentenárias (Kenis et al., 2007). Nesse caso, principalmente patógenos, cuja detecção requer técnicas apuradas, deveriam ser objeto de análise de risco de pragas para uma regulamentação futura (Eschen et al., 2015), o que deve ser levado em conta nas ações a serem realizadas no Brasil.

Das espécies de pragas interceptadas à época ausentes no Brasil, seis foram, posteriormente, encontradas em território nacional: os ácaros Aceria tosichella Keifer (Prostigmata: Eriophyidae) (Pereira et al., 2009), Oxycenus maxwelli Keifer (Prostigmata: Eriophyidae) (Reis et al., 2011); e os vírus Sweet potato latent virus (SPLV), Sweet potato chlorotic fleck virus (SPLV) (Kroth et al., 2001), Lily symptomless virus (LSV) e Lily mottle virus (LMoV) (Rivas, 2010). Três dessas pragas foram interceptadas mais de uma vez: O. maxwelli, com três interceptações sobre oliveira (Olea europaea L.); LSV, com 21 interceptações em lírio (Lilium spp.); e LMoV, com duas interceptações, também sobre lírio. As pragas ainda ausentes no Brasil, que também foram interceptadas mais de uma vez, incluem as raças de nematoides Ditylenchus dipsaci, com sete interceptações em batata (Solanum tuberosum), bromélia (Bromelia sp.), melão (Cucumis melo), soja (Glycine max), aveia (Avena sp.) e milho (Zea mays); Anguina sp. em trigo (Triticum aestivum); Aphelencoides blastophorus em dendê (Elaeis oleifera) e videira (Vitis vinifera), e Globodera sp. em batata. $\mathrm{O}$ ácaro Brevipalpus chilensis foi interceptado três vezes em frutos de kiwi e uva, e o fungo Drechslera bipsetata uma vez em trigo (Triticum spp.) e outra em triticale (X Triticosecale).

Entre as 520 espécies vegetais importadas, apenas 43 apresentaram pragas quarentenárias ou pragas ausentes não regulamentadas. Essa constatação indica que interceptações de pragas exóticas quarentenárias de importância são feitas apenas em um número restrito de vias de ingresso (Eschen et al., 2015). A espécie vegetal em que houve o maior número de espécies de pragas interceptadas foi a oliveira, com 11 espécies de pragas, seguida de videira $\operatorname{com} 8$, trigo $\operatorname{com} 6$, batata $\operatorname{com} 5$ 
e arroz (Oryza sativa) com 4 espécies interceptadas. Entretanto, o maior número absoluto de interceptações ocorreu sobre lírio. Aproximadamente metade das interceptações foi detectada no conjunto formado por lírio, oliveira, trigo, uva e batata (Figura 2). De forma geral, a maioria das pragas interceptadas ocorreu sobre plantas ou partes de plantas, principalmente com origem de regiões de clima temperado. Esse resultado é explicado pela predominância da origem do material vegetal analisado, proveniente da Europa e da América do Norte. Tanto o lírio como a oliveira foram importados de países da Europa, como Holanda e Itália, e a maior quantidade de sementes foi oriunda dos Estados Unidos.

O milho foi o produto mais importado (14,3\% do total de importações); contudo, para ele, apenas três interceptações de praga no período compreendido foram registradas. $\mathrm{O}$ milho foi, entre as espécies vegetais com relatos de interceptação, a de menor percentual de incidência de pragas. Os dados obtidos permitem distinguir um conjunto de importações de espécies com baixa incidência de interceptações de pragas (milho, algodão, arroz e trigo) e outro de espécies com alto percentual de interceptações (oliveira, lírio,

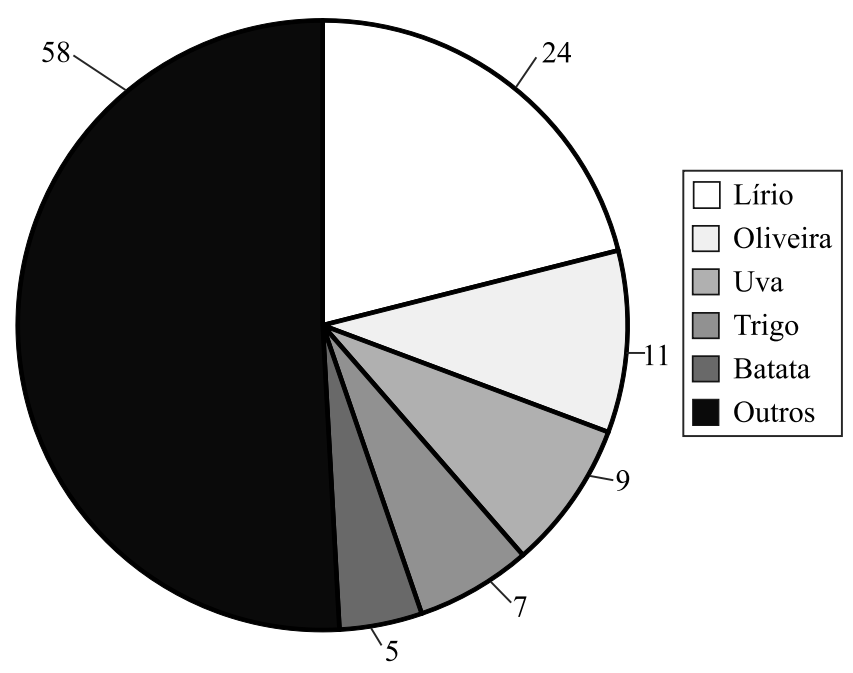

Figura 2. Número de importações com interceptações de pragas quarentenárias e ausentes sem regulamentação, por espécie de material vegetal importado. Dados da Estação Quarentenária de Germoplasma Vegetal da Embrapa Recursos Genéticos e Biotecnologia (1977-2013). maçã e videira) (Tabela 2). Plantas ornamentais, mudas para viveiros, frutos e flores de corte são vias principais para introdução de pragas como insetos, ácaros, fungos e bactérias (McCullough et al., 2006; Eschen et al., 2015), e esse fato é confirmado pelo conjunto de interceptações na EQGV. Por outro lado, não foi detectada nenhuma praga quarentenária ou ausente não regulamentada em café (Coffea arabica) (21 importações de nove países) e citros (Citrus spp.) (28 importações de dez países), culturas para as quais há um grande número de pragas descritas.

Em relação ao tipo de material vegetal importado, o número de interceptações que ocorreram em material de propagação vegetativa (estacas, mudas, gemas, bulbos) foi o dobro do número relativo às sementes botânicas. A interceptação de pragas foi mais alta sobre o material de propagação vegetativa (teste de $\chi^{2}=383,246 \mathrm{com}$ $\mathrm{p}<0,0001, \mathrm{GL}=1$ ), ou seja, a incidência de pragas foi, proporcionalmente, 21 vezes maior sobre o material de propagação vegetativa do que em sementes botânicas. A proporção de importações de material vegetativo infectado e/ou infestado por país variou de 0 a 80,5\%. Quanto maior o percentual de material de propagação vegetativa na importação de germoplasma vegetal de cada país, maior o número de interceptações observadas.

Tabela 2. Número de importações e porcentagem de detecção de pragas por espécie vegetal. Dados da Estação Quarentenária de Germoplasma Vegetal da Embrapa Recursos Genéticos e Biotecnologia (1977-2013).

\begin{tabular}{lcc}
\hline Espécie vegetal & Importações & $\begin{array}{c}\text { Importações com } \\
\text { detecção (\%) }\end{array}$ \\
\hline Milho (Zea mays) & 755 & 0,40 \\
Trigo (Triticum spp.) & 326 & 2,15 \\
Arroz (Oryza sativa) & 274 & 1,82 \\
Batata (Solanum tuberosum) & 160 & 3,12 \\
Algodão (Gossypium sp.) & 126 & 0,79 \\
Lírio (Lilium spp.) & 59 & 40,68 \\
Uva (Vitis spp.) & 47 & 19,01 \\
Pinus spp. & 34 & 2,94 \\
Eucalipto (Eucalyptus spp.) & 30 & 3,33 \\
Braquiária (Brachyaria spp.) & 29 & 3,44 \\
Kiwi (Actinidia deliciosa) & 23 & 4,34 \\
Batata-doce (Ipomoea batatas) & 21 & 9,52 \\
Milheto (Pennisetum glaucum) & 21 & 3,57 \\
Maçã (Pyrus malus) & 16 & 18,75 \\
Oliveira (Olea europaea) & 15 & 73,33 \\
Tulipa (Tulipa sp.) & 10 & 10,00 \\
Outras & 77 & 16,83 \\
\hline
\end{tabular}

Pesq. agropec. bras., Brasília, v.51, n.5, p.494-501, maio 2016 DOI: $10.1590 / \mathrm{S} 0100-204 \mathrm{X} 2016000500009$ 
Houve correlação positiva entre o número total de importações e o número total de detecções $(\mathrm{r}=0,543$, $\mathrm{p}=0,016, \quad \mathrm{GL}=17)$. Entretanto, a proporção de importações nas quais houve interceptação de praga foi diferente entre os países (Teste $\mathrm{G}=518,49, \mathrm{GL}=17$, $\mathrm{p}<0,0001)$. Isso pode ser explicado pelas diferenças de perfil do conjunto do material vegetal importado de cada país. O fator definido como "proporção de material de propagação vegetativa na importação" foi o fator que melhor explicaria a interceptação de pragas em germoplasma e material comercial de países (Figura 3). Torna-se evidente que se deve considerar o tipo de material vegetal importado como um fator mais importante no risco de introdução de pragas do que somente a origem do material.

Considerando que as análises fitossanitárias nas estações quarentenárias são muito mais criteriosas que as inspeções de material comercial, muitas associações raras ou desconhecidas de pragas com espécies deplantas podem ser reportadas. Assim, dados de interceptação obtidos em estações quarentenárias podem contribuir de forma mais efetiva para formular as políticas

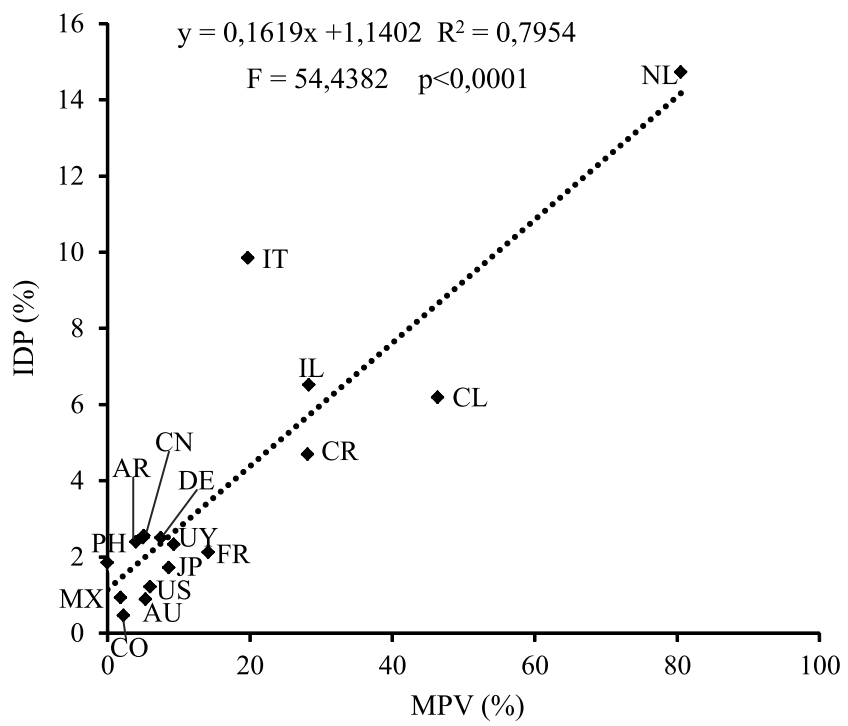

Figura 3. Material de propagação vegetativa (MPV) e importações com interceptações de pragas quarentenárias ou ausentes do Brasil sem regulamentação (IDP). Cada ponto representa as importações de germoplasma e material comercial de países. Estação Quarentenária de Germoplasma (EQGV) da Embrapa Recursos Genéticos e Biotecnologia (1977-2013). AR, Argentina; AU, Austrália; CL, Chile; CN, China; CO, Colômbia; CR, Costa Rica; DE, Alemanha; FR, França; IL, Israel; IT, Itália; JP, Japão; MX, México; NL, Holanda; PH, Filipinas; US, Estados Unidos; UY, Uruguai. públicas que visem ao manejo do risco de introdução de pragas pelo comércio internacional de plantas e suas partes, qualquer que seja o uso proposto. Os resultados obtidos apontam para necessidade premente de revisão da atual lista de pragas quarentenárias do Brasil.

\section{Conclusões}

1. Material de propagação vegetativa (mudas, bulbos, estacas) apresentam maior risco de introdução de pragas que sementes botânicas.

2. A compilação e análise de dados de interceptações de pragas evidenciam a importância da quarentena de pós-entrada na prevenção de introdução de pragas.

\section{Referências}

BEBBER, D.P.; HOLMES, T.; GURR, S.J. The global spread of crop pests and pathogens. Global Ecology and Biogeography, v.23, p.1398-1407, 2014. DOI: 10.1111/geb.12214.

BRASIL. Instrução normativa ${ }^{\circ}$ 59, de 18 de dezembro de 2013. Diário Oficial [da] República Federativa do Brasil, Brasília, DF, 19 dez. 2013. Seção 1, p.91-92.

ESCHEN, R.; ROQUES, A.; SANTINI, A. Taxonomic dissimilarity in patterns of interception and establishment of alien arthropods, nematodes and pathogens affecting woody plants in Europe. Diversity and Distributions: a Journal of Conservation Biogeography, v.21, p.36-45, 2015. DOI: 10.1111/ddi.12267.

GONZAGA, V.; BENITO, N.P.; LOPES-DA-SILVA, M.; ROCHA, H.M.C.; NAVIA, D. Quarentena vegetal no Brasil. In: VILELA, E.F.; ZUCCHI, R.A. (Ed.). Pragas introduzidas no Brasil: insetos e ácaros. Piracicaba: FEALQ, 2015. p.67-108.

GUERRA, M.P.; ROCHA, F.S.; NODARI, R.O. Biodiversidade, recursos genéticos vegetais e segurança alimentar em cenário de ameaças e mudanças. In: VEIGA, R.F. de A.; QUEIRÓZ, M.A. de (Ed.). Recursos fitogenéticos: a base da agricultura sustentável no Brasil. Viçosa: Ed. UFV, 2015. p.39-52.

HULME, P.E. Trade, transport and trouble: managing invasive species pathways in an era of globalization. Journal of Applied Ecology, v.46, p.10-18, 2009. DOI: 10.1111/j.1365-2664.2008.01 600.x.

INTERNATIONAL PLANT PROTECTION CONVENTION. Glossary of phytosanitary terms. Roma: IPPC, 2012. 27p. Available at: <https://www.ippc.int/publications/ glossary-phytosanitary-terms $>$. Accessed on: 29 dez. 2014.

INTERNATIONAL PLANT PROTECTION CONVENTION. New revised text International Plant Protection Convention. Roma: IPPC, 1997. Available at: <https:/www.ippc.int/en/coreactivities/governance/convention-text/>. Accessed on: $29 \mathrm{dez}$. 2014.

KARNKOWSKI, W. Quarantine insects, mites and nematodes intercepted in consignments of ornamental plants imported 
to Poland in 1993-1998. Progress in Plant Protection, v.39, p.312-320, 1999.

KENIS, M.; RABITSCH, W.; AUGER-ROZENBERG, M.A.; ROQUES, A. How can alien species inventories and interception data help us prevent insect invasions? Bulletin of Entomological Research, v.97, p.489-502, 2007. DOI: 10.1017/ S0007485307005184.

KROTH, L.L.; FUENTES, S.; SALAZAR, L.F.; DANIELS, J. Detecção sorológica de vírus por NCM-Elisa em lavouras de batata-doce no Estado do Rio Grande do Sul, Brasil. Revista Brasileira de Agrociência, v.7, p.117-119, 2001. DOI: 10.18539/ cast.v7i2.375.

LEGRAND, P. Importations de vigne dans l'union europeenne et securité phytosanitaire: le role indispensable de la quarantine. Bulletin de I'OIV, v.85, p.481-489, 2012.

LOPES-DA-SILVA, M.; SANCHES, M.M.; STANCIOLI, A.R.; ALVES, G.; SUGAYAMA, R. The role of natural and human-mediated pathways for invasive agricultural pests: a historical analysis of cases from Brazil. Agricultural Sciences, v.5, p.634-646, 2014. DOI: 10.4236/as.2014.57067.

MARINHO, V.L. de A.; MENDES, M.A.S.; TENENTE, R.C.V.; BATISTA, M. de F.; OLIVEIRA, M.R.V.; MARQUES, A.S. dos A.; URBEN, A.F.; FONSECA, J.N.L.; GONZAGA, V. Procedimentos e métodos utilizados no intercâmbio e quarentena de germoplasma vegetal. Brasília: Embrapa Recursos Genéticos e Biotecnologia, 2003. 47p. (Embrapa Recursos Genéticos e Biotecnologia. Documentos, 103).

MARQUES, A.S. dos A.; PARENTE, P.M.G.; MARINHO, V.L. de A.; BUSO, G.S.C. A quarentena e o intercâmbio de germoplasma vegetal no Brasil: a atuação do Cenargen. Pesquisa Agropecuária Brasileira, v.30, p.143-154, 1995.

MCCOUCH, S.; BAUTE, G.J.; BRADEEN, J.; BRAMEL, P.; BRETTING, P.K.; BUCKLER, E.; BURKE, J.M.; CHAREST, D.; CLOUTIER, S.; COLE, G.; DEMPEWOLF, H.; DINGKUHN, M.; FEUILLET, C.; GEPTS, P.; GRATTAPAGLIA, D.; GUARINO, L.; Scott JACKSON; KNAPP, S.; LANGRIDGE, P.; LAWTON-RAUH, A.; LIJUA, Q.; LUSTY, C.; MICHAEL, T.; MYLES, S.; NAITO, K.; NELSON, R.L.; PONTAROLLO, R.; RICHARDS, C.M.; RIESEBERG, L.; ROSS-IBARRA, J.; ROUNSLEY, S.; HAMILTON, R.S.; SCHURR, U.; STEIN, N.; TOMOOKA, N.; KNAAP, E. van der; TASSEL, D. van; TOLL, J.; VALLS, J.; VARSHNEY, R.K.; WARD, J.; WAUGH, R.; WENZL, P.; ZAMIR, D. Agriculture: feeding the future. Nature, v.499, p.23-24, 2013. DOI: 10.1038/499023a.
MCCULLOUGH, D.G.; WORK, T.T.; CAVEY, J.F.; LIEBHOLD, A.M.; MARSHALL, D. Interceptions of nonindigenous plant pests at US ports of entry and border crossings over a 17- year period. Biological Invasions, v.8, p.611-630, 2006. DOI: 10.1007/ s10530-005-1798-4.

PEREIRA, P.R.V. da S.; NAVIA, D.; SALVADORI, J.R.; LAU, D. Occurrence of Aceria tosichella in Brazil. Pesquisa Agropecuária Brasileira, v.44, p.539-542, 2009. DOI: 10.1590/ S0100-204X2009000500015.

REIS, P.R.; OLIVEIRA, A.F. de; NAVIA, D. First record of the olive bud mite Oxycenus maxwelli (Keifer) (Acari: Eriophyidae) from Brazil. Neotropical Entomology, v.40, p.622-624, 2011. DOI: $10.1590 /$ S1519-566X2011000500017.

RIVAS, E.B. Lily symptomless virus no Brasil. São Paulo: Instituto Biológico, 2010. 5p. (Instituto Biológico. Documento técnico, 004).

SINGH, A.K.; MAHINGHARA, B.K.; HALLAN, V.; RAM, R.; ZAIDI, A.A. Recombination and phylogeographic analysis of Lily symptomless virus. Virus Genes, v.36, p.421-427, 2008. DOI: 10.1007/s11262-008-0197-1.

STANCIOLI, A.R.; SUGAYAMA, R.L. Análise de risco de pragas. In: SUGAYAMA, R.L.; LOPES-DA-SILVA, M.; SILVA, S.X.B.; RIBEIRO, L.R.; RANGEL, L.E.P. (Ed.). Defesa vegetal: fundamentos, ferramentas, políticas e perspectivas. Belo Horizonte: Sociedade Brasileira de Defesa Agropecuária, 2015. p.165-182.

SUGAYAMA, R.L.; IEDE, E.T.; STANCIOLI, A.R.; ALVES, G.A.; OLIVEIRA, I.M.; DIAS, J.A. Ameaças fitossanitárias. In: SUGAYAMA, R.L.; LOPES-DA-SILVA, M.; SILVA, S.X. de B.; RIBEIRO, L.R.; RANGEL, L.E.P. (Ed.). Defesa vegetal: fundamentos, ferramentas, políticas e perspectivas. Belo Horizonte: Sociedade Brasileira de Defesa Agropecuária, 2015. p.449-471.

WARWICK, D.R.N.; URBEN, A.F.; TENENTE, R.C.V.; FONSECA, J.N.L. Plant quarantine activities at the National Centre of Genetic Resources (EMBRAPA) in Brazil. Seed Science and Technology, v.11, p.1225-1229, 1983.

WATERWORTH, H.E.; WHITE, G.A. Plant introductions and quarantine: the need for both. Plant Disease, v.66, p.87-90, 1982. DOI: 10.1094/PD-66-87.

ZHANG, G.M.; LING, X.Y.; FENG, J.J.; CHENG, Y.H.; ZHENG, Y.; LI, Y.N.; LONG, H.; LI, F.R.; WANG, Y.; JIAO, Y.; XIANG, C.Y.; YU, D.J.; KANG, L. Overview of plant quarantine in Shenzhen, China. Plant Pathology and Quarantine, v.1, p.103-114, 2011.

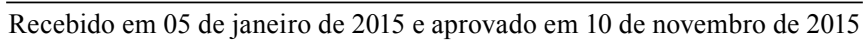

